\title{
Management of Pneumothorax-Update with Emphasis on Interventional and Minimally Invasive Procedures
}

\author{
Pnömotoraks Yönetimi-Girişimsel ve Minimal Invazif Işlemler için \\ Güncelleme
}

Julius P. Janssen

Canisius Wilhelmina Hospital, Department of Pulmonary Diseases, The Netherlands

\begin{abstract}
Pneumothorax is a disease of the lung, defined as the presence of air in the pleural space. Most cases of pneumothorax occur spontaneously. A spontaneous pneumothorax can be defined as a primary or secondary pneumothorax. The majority of patients will present with sudden onset of chest pain, dyspnoea or both. Treatment decisions are mainly based on symptoms. The primary goal of treatment for primary spontaneous pneumothorax is reexpansion of the lung. Treatment options for primary spontaneous pneumothorax are simple manual aspiration, chest tube drainage and surgical treatment. In this review, the focus will be on the diagnosis and treatment of primary spontaneous pneumothorax.
\end{abstract}

Keywords: Pneumothorax, thoracoscopy, treatment

\section{ÖZET}

Pnömotoraks plevral boşlukta hava bulunması şeklinde tanımlanan akciğer hastalı̆̆ıdır. Pnömotoraks olgularının çoğu spontan gelişir. Spontan pnömotoraks primer veya sekonder pnömotoraks olarak sınıflandırılır. Hastaların çoğu ani başlayan gögüs ağrısı, dispne ya da her ikisi ile başvurur. Primer spontan pnömotoraks tedavisinin temel amaci akciğerin re-ekspansiyonudur. Primer spontan pnömotoraksta tedavi seçenekleri, basit manuel aspirasyon, göğüs tüpü ile drenaj ve cerrahi tedavidir. Bu derlemede primer spontan pnömotoraksın tanı ve tedavisi üzerinde durulmuştur.

Anahtar Kelimeler: Pnömotoraks, torakoskopi, tedavi

\section{INTRODUCTION}

Pneumothorax is a disease of the lung, defined as the presence of air in the pleural space. Most cases of pneumothorax occur spontaneously. A spontaneous pneumothorax can be defined as a primary or secondary pneumothorax. In primary spontaneous pneumothorax (PSP), the pneumothorax occurs spontaneously, in the absence of a known underlying disease. In secondary pneumothorax, the pneumothorax is caused by an underlying disease like chronic obstructive pulmonary disease, cystic fibrosis, tuberculosis or interstitial lung disease. In rare cases, spontaneous pneumothorax occurs in conjunction with menstruation and is called catamenial pneumothorax. A traumatic pneumothorax does not occur spontaneously, but can be iatrogenic or due to a trauma. In this review, the focus will be on the diagnosis and treatment of PSP.

\section{CLINICAL PRESENTATION OF PSP}

The incidence of PSP is estimated at $18-28 / 10^{5} /$ year for men and $1.2-6 / 10^{5} /$ year for women. PSP tends to occur more often in tall and thin patients. There is a family history in about $10 \%$ of cases. Smoking increases the risk for pneumothorax by at least nine-fold. The peak incidence is between 20 and 25 years.

The majority of patients will present with sudden onset of chest pain, dyspnoea or both. Patients with secondary spontaneous pneumothorax, in general, have more symptoms than pa-

Received date / Geliş tarihi: 27.12.2012 Accepted date / Kabul tarihi: 22.01.2013

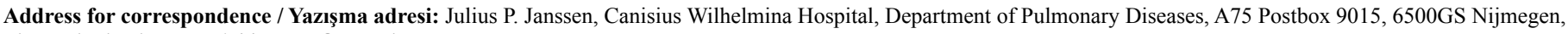
The Netherlands; E-mail: j.janssen@cwz.nl

(C) Copyright 2013 Turkish Respiratory Society (TRS) • (C) Telif hakkı 2013 Türkiye Solunum Araştırmaları Derneği (TÜSAD)

Solunum 2013;15(1):1-4 • DOI: 10.5152/solunum.2013.001

Available online at www.solunum.org.tr/dergi • Makalelerin tam metinlerine www.solunum.org.tr/dergi adresinden ulaşabilirsiniz. 
tients with PSP. In the majority of patients, the symptoms will occur during rest. PSP hardly ever occurs during exercise.

\section{DIAGNOSIS}

The key diagnostic test is the chest $\mathrm{x}$-ray. Additional chest $\mathrm{x}$-ray in an expiratory position, which was recommended previously, has no additional value and has been abandoned. In a pneumothorax, there is a space visible between the border of the lung and the chest wall. In a large spontaneous pneumothorax, a shift of the mediastinum to the contralateral side may occur. However, this sign does not always mean a tension pneumothorax.

In some cases of severe bullous emphysema, bullous disease can be hard to differentiate from pneumothorax. In such cases, a computed tomography (CT) scan of the chest will provide additional information.

\section{SIZE OF PNEUMOTHORAX}

There are several definitions of a "small" and "large" pneumothorax. According to the ACCP guidelines, a large pneumothorax exists if the distance of the apex of the lung to the cupula is more than $3 \mathrm{~cm}$ (1). The more recent BTS guidelines define a large pneumothorax if the distance between the lung margin and the chest wall is more than $2 \mathrm{~cm}(2)$.

For an exact calculation of the size, a CT scan of the chest is the gold standard. This is seldom necessary and is not part of common daily practice.

\section{DOES THE SIZE OF A PNEUMOTHORAX MATTER?}

Because of different definitions for the size of a pneumothorax, the current definition of "small" or "large" pneumothorax may be confusing. In a study by Kelly, the ACCP guidelines tended to overestimate the size of pneumothorax, as compared to the BTS guidelines (3). In their study of 94 cases of pneumothorax, there was agreement on the size of a pneumothorax in $47 \%$ of cases. However, $49 \%$ had a large pneumothorax according to the ACCP guidelines, and only $10 \%$ according to the BTS guidelines.

In daily practice, the importance of the size of a pneumothorax is limited. Treatment decisions are mainly based on symptoms. Conservative treatment (observation) is indicated in the first occurrence of a small pneumothorax without (severe) symptoms. In the case of a large PSP without symptoms, conservative treatment is also an option, although re-expansion may take a long time (six weeks or longer in complete collapse of the lung). However, in large PSP and in symptomatic pneumothorax, treatment is indicated according to the BTS guidelines (2).

\section{TREATMENT OF THE FIRST PSP EPISODE}

The primary goal in the treatment of PSP is re-expansion of the lung. The guidelines do not agree on the treatment for PSP.
According to the ACCP guidelines, which date back to 2001, chest tube drainage is the treatment of choice (1). Attachment of the chest tube to a water seal-suction device makes hospitalisation and immobilisation necessary, which is a serious drawback of this treatment.

Simple manual aspiration has gained popularity in recent years, after the landmark study by Noppen (4). An alternative to manual aspiration may be a small-bore $(<14 \mathrm{f})$ Seldinger chest drain attached to a Heimlich seal. Manual aspiration is an outpatient procedure and the attachment of a small-bore Seldinger drain to a Heimlich valve facilitates ambulation and outpatient care. The study by Noppen showed equivalent success of manual aspiration and chest tube drainage; this conclusion was repeated in a meta-analysis (5). There have been no randomised controlled studies that compared manual aspiration to smallbore Seldinger drains in an ambulatory setting, but Seldinger drains have the same success rates as larger drains (6).

The advantages of manual aspiration or small-bore Seldinger drains over traditional large-bore drains are obvious: an outpatient setting, meaning no hospitalisation or immobilisation, less pain and no scar. For these reasons, a minimally invasive outpatient procedure, be it manual aspiration or Seldinger chest drain, is to be preferred over chest tube drainage and water seal.

\section{TREATMENT AFTER RECURRENCE OR FAILURE OF MANUAL ASPIRATION}

According to the BTS guidelines, chest tube drainage using a small tube $(<14 \mathrm{~F})$ is recommended after failure of manual aspiration, being the usual practice in the United Kingdom (2). A study by Chen et al. compared the results of chest tube drainage and thoracoscopic surgery after unsuccessful aspiration of PSP (7). In a group of 164 patients, manual aspiration was unsuccessful in 52. Of these, 30 underwent video-assisted thoracoscopic surgery (VATS), and 22 underwent chest tube drainage. The thoracoscopic treatment was more cost-effective and resulted in fewer complications and a shorter hospital stay. The eventual failure rate of the chest tube group was $41 \%$. It is, therefore, questionable if chest tube drainage is the treatment of choice after failure of manual aspiration.

In a previous randomised study, Tschopp et al. compared chest tube drainage to thoracoscopy with talc poudrage (8). In this study of 108 patients with PSP, the failure rate was $21 \%$ in the chest tube group versus $2 \%$ in the thoracoscopy group. The immediate and long-term recurrence rate was $31 \%$ for the chest tube group and $5 \%$ for the thoracoscopy/talc group after a mean follow-up of more than 15 months.

There was no difference in the residual pain and working ability in these groups. Pleural drainage is cheaper than thoracoscopy with talc pleurodesis. However, because of the high failure rate in the chest tube drainage group, thoracoscopy with talc pleurodesis is eventually more cost-effective. 
Table 1. Recurrence rates of available treatment options for primary spontaneous pneumothorax

\begin{tabular}{l|c|}
\hline Re-expansion only & Recurrence rate \\
\hline Wait and see & $30-50 \%^{1}$ \\
Aspiration & $30-50 \%{ }^{1}$ \\
Chest tube drainage & $30-50 \%^{1}$ \\
\hline Recurrence prevention & \\
\hline
\end{tabular}

Pulmonary intervention:

Talc slurry $8 \%{ }^{2}$

Thoracoscopy/talc poudrage $\quad 5 \%$

Surgical intervention
$\begin{aligned} & \text { Open thoracotomy/pleurectomy } \\ & \text { VATS/pleurectomy }\end{aligned}$
$\begin{aligned} & 1 \% \\ & \text { VA The estimated recurrence rate increases after every episode of spontaneous } \\ & \text { pneumothorax. } \\ & \text { 2The recurrence rate after talc slurry pleurodesis has not been well-assessed. }\end{aligned}$

\section{THE PLACE OF SURGICAL TREATMENT FOR RECURRENT PSP}

The aim of surgical treatment in recurrent PSP is the prevention of a further recurrence. After each episode of PSP, the risk of recurrence increases, to over $75 \%$ after the third episode, if pleurodesis or pleurectomy is not performed. Prevention of further recurrence is, therefore, mandatory. The time of treatment for recurrence prevention after the first episode of PSP is subject to discussion. According to the ACCP Delphi Consensus, 85\% of the participating experts thought that treatment for recurrence prevention should only be performed after the second episode of PSP (1).

There are several invasive procedures to perform for recurrence prevention: thoracoscopy with talc poudrage (performed mostly by pulmonologists), VATS with (partial) pleurectomy or talc poudrage, a thoracotomy with partial or complete pleurectomy (performed by a thoracic surgeon). Rubbing of the pleura is no longer performed, as the results are inferior to talc pleurodesis or pleurectomy. Resection of blebs or bullae can be included in the surgical procedure. It is not clear which of these is the procedure of choice; there are no direct comparative and randomised studies for thoracotomy versus VATS, or VATS versus thoracoscopy with talc poudrage.

Moreover, although resection of blebs and bullae is a standard procedure during surgical treatment of PSP, the rationale for this resection has not been proven. There have been no randomised trials to compare bullectomy by VATS or thoracotomy with and without pleurectomy.

In the BTS guidelines, it is stated that "prevention of recurrence should be undertaken surgically, as the recurrence is far less than that following medical pleurodesis". This is not true; the recurrence rate of VATS treatment is $5 \%$, which is the same as that after thoracoscopy with talc pleurodesis (8). Open thoracotomy with pleurectomy remains the procedure with the lowest recurrence rate $(1 \%)$, but has the important disadvantages of longer hospital stay and more postoperative pain, sometimes lasting for a long period $(9,10)$.

\section{IS RESECTION OF BLEBS AND BULLAE NECESSARY?}

In the majority of patients with recurrent PSP, blebs or bullae (the so-called "emphysema-like changes") are found at the apex of the lung. This has been confirmed in a study using CT (11). In this study, "emphysema-like changes" were demonstrated on the CT scans in $81 \%$ of non-smoking, non- $\alpha-1$-antitrypsin deficient males with previous PSP, and in only $20 \%$ of age- and smoking-matched controls without PSP. Although "emphysema-like changes" occur in the majority of patients with PSP, there is no proof that they are the actual cause of PSP.

\section{LESS INVASIVE TREATMENT AND PREVENTION OF RECURRENCE IN PSP}

\section{A guideline for the daily practice}

From the past until today, there has been a discussion on the treatment of PSP, and treatment is mostly based upon habit or conviction. There is little evidence in the literature to prove the superiority of one treatment over the other. There exists only one recent guideline on the treatment of PSP, which merely reflects the common practice in the UK (2). It is, therefore, not easy to define the optimal treatment for PSP.

In this era of minimally invasive treatments, it is obvious that a less invasive treatment should have advantages over an invasive treatment for the patient. Chest tube drainage does not add any advantage over manual aspiration or ambulatory management with a Seldinger tube. With a chest tube, the patient is hospitalised and immobilised, but the recurrence rate is the same as that after less invasive methods of lung re-expansion (see Table 1 for an overview of treatment modalities and their recurrence rates). Large-bore chest tube drainage should therefore be abandoned as the standard treatment for PSP, except for emergency situations.

Another subject of discussion is the necessity of recurrence prevention after the first episode of PSP. Although the majority of pulmonary physicians will perform only pleurodesis after the first recurrence of PSP, many patients (who are mostly young, active and travelling frequently) will not be happy with a recurrence rate of at least $30 \%$.

In our hospital, at the first event of PSP, the patient is given the choice of manual aspiration or thoracoscopy with talc poudrage (See Figure 1 for the treatment algorithm of PSP in our hospital). In our experience, the majority of patients choose thoracoscopy with talc poudrage as the primary treatment, in order to reduce the risk of recurrence.

\section{SURGICAL CASES OF PSP}

In the following circumstances, patients with PSP should be sent to the thoracic surgeon: 


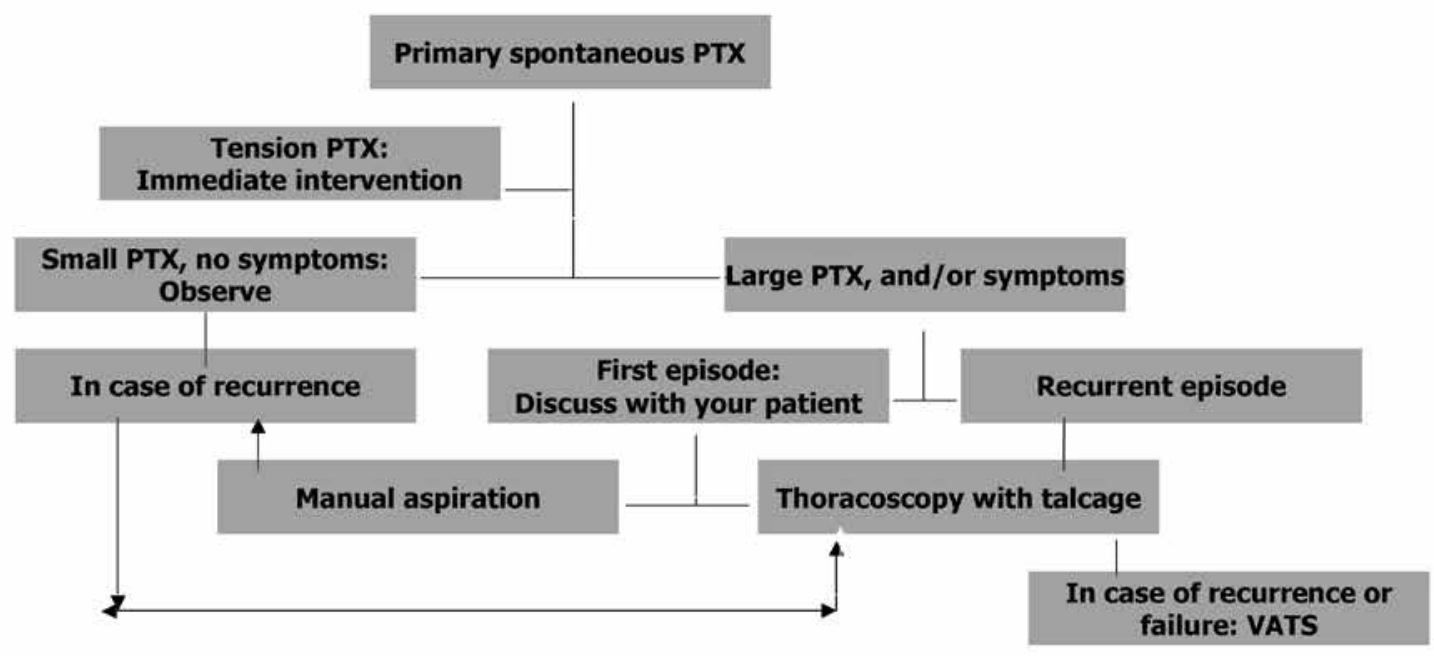

Figure 1. The treatment algorithm in our hospital (PTX: pneumothorax). In case of the first PSP that needs treatment, the options (manual aspiration or thoracoscopy with talc poudrage) are discussed with the patient, together with advantages and disadvantages of both options.

1. Persistent air leak with no tendency to diminish 48 hours after thoracoscopy with talc poudrage,

2. Failure of the lung to re-expand 48 hours after thoracoscopy with talc poudrage,

3. Recurrent collapse of the lung after clamping of the tube prior to the removal of drainage,

4. Ruptured bulla found during thoracoscopy.

\section{CONCLUSION}

The absence of well-performed randomised studies has resulted in a lack of evidence for the optimal treatment for PSP. A well-founded choice from all the available treatment options is therefore difficult.

The way forward is to use minimally invasive procedures to obtain lung re-expansion (manual aspiration, small-bore Seldinger drain) as an outpatient-based treatment. In-hospital treatment should be reserved for invasive procedures that aim for a reduction of recurrence, such as thoracoscopy with talc poudrage or surgical procedures.

The role of routine removal of non-ruptured blebs and bullae is still unclear and needs to be elucidated in future studies.

\section{REFERENCES}

1. Baumann MH, Strange C, Heffner JE, Light R, Kirby TJ, Klein J, et al. Management of spontaneous pneumothorax: an American College of Chest Physicians Delphi consensus statement. Chest 2001; 119: 590 - 602. [CrossRef]

2. MacDuff A, Arnold A, Harvey J, on behalf of the BTS Pleural Disease Guideline Group. Management of spontaneous pneumotho- rax: British Thoracic Society pleural disease guideline 2010. Thorax 2010; 65 Suppl 2: ii18-ii31. [CrossRef]

3. Kelly AM, Druda D. Comparison of size classification of primary spontaneous pneumothorax by three international guidelines: a case for international consensus? Respir Med 2008; 102: 1830-2. [CrossRef]

4. Noppen M, Alexander P, Driesen P, Slabbynck H, Verstraeten A. Manual aspiration versus chest tube drainage in first episodes of primary spontaneous pneumothorax: a multicenter, prospective, randomized pilot study. Am J Respir Crit Care Med 2002; 165: 1240-4. [CrossRef]

5. Wakai A, O'Sullivan RG, McCabe G. Simple aspiration versus intercostal tube drainage for primary spontaneous pneumothorax in adults. Cochrane Database Syst Rev 2007; 24: CD004479.

6. Vedam H, Barnes DJ. Comparison of large- and small-bore intercostal catheters in the management of spontaneous pneumothorax. Intern Med J 2003; 33: 495-9. [CrossRef]

7. Chen JS, Hsu HH, Tsai KT, Yuan A, Chen WJ, Lee YC. Salvage for unsuccessful aspiration of primary pneumothorax: thoracoscopic surgery or chest tube drainage? Ann Thorac Surg 2008; 85: 1908-13. [CrossRef]

8. Tschopp JM, Boutin C, Astoul P, Janssen JP, Grandin S, Bolliger CT, et al. Talcage by medical thoracoscopy for primary spontaneous pneumothorax is more cost-effective than drainage: a randomised study.Eur Respir J 2002; 20: 1003-9. [CrossRef]

9. Al-Tarshihi MI. Comparison of the efficacy and safety of video-assisted thoracoscopic surgery with the open method for the treatment of primary pneumothorax in adults. Ann Thorac Med 2008; 3: 9-12. [CrossRef]

10. Sedrakyan A, van der Meulen J, Lewsey J, Treasure T. Video assisted thoracic surgery for treatment of pneumothorax and lung resections: systematic review of randomised clinical trials. BMJ 2004; 329: 1008. [CrossRef]

11. Bense L, Lewander R, Eklund G, Hedenstierna G, Wiman LG. Nonsmoking, non-alpha 1-antitrypsin deficiency-induced emphysema in nonsmokers with healed spontaneous pneumothorax, identified by computed tomography of the lungs. Chest 1993; 103: 433-8. [CrossRef] 